\title{
DESAFIOS DO SABER-FAZER DOCENTE NA CONTEMPORANEIDADE
}

\begin{tabular}{l}
\hline TEACHERS' KNOW-HOW CHALLENGES IN CONTEMPORARY \\
\hline DESAFÍOS DEL SABER-HACER DOCENTE EN LA CONTEMPORANEIDAD \\
\hline Celso José Martinazzo ${ }^{1}$ \\
Óberson Isac Dresch ${ }^{2}$
\end{tabular}

PALAVRAS-ChaVE: Formação docente. Pensamento complexo. Conhecimento.

ABSTRACT: The text has the objective of reflecting about teachers' know-how challenges given the complexity of the contemporary world. The purpose is to highlight the importance and relevance of the cognitive dimension in teacher training processes. The understanding of this issue leads us to investigate the epistemological assumptions that historically guided the process of education and teacher trainings. The understanding of the knowledge process is a key requirement for the school education success and, this is why, it should receive special attention in teacher trainings. Studies point to the need of a paradigmatic reform in order to operate with the knowledge that transcends the modern episteme, producer of conceptions and simplifying and fragmenting practices of know-how as well as the utilitarian bias of technical skills. The new paradigmatic references seek to work based on the principles of complex thinking that include theory and practice in an antagonistic, competitive and complementary way.

KEYWORDS: Teacher training. Complex thinking. Knowledge.

RESUMEN: El texto tiene como objetivo reflexionar sobre los desafíos del saber-hacer docente ante la complejidad del mundo contemporáneo. Se busca destacar la importancia y la pertinencia de la dimensión cognitiva en el proceso de formación de profesores. La comprensión de esta temática nos remite a investigar los presupuestos epistemológicos que, históricamente, orientaron el proceso de educación escolar y la formación del profesor. Comprender el proceso del conocimiento es un requisito fundamental para el éxito de la educación escolar y, por lo tanto, debe merecer una atención especial en la formación docente. Estudios apuntan a la necesidad de una reforma paradigmática en el modo de operar con el conocimiento que trasciende la episteme moderna, productora de concepciones y prácticas simplificadoras y fragmentadoras del saber hacer, así como el sesgo utilitarista de las competencias técnicas. Las nuevas referencias paradigmáticas buscan operar con base en los principios del pensamiento complejo que contemplan teoría y práctica de forma antagónica, concurrente y complementaria.

PAlabraS Clave: Formación docente. Pensamiento complejo. Conocimiento.

\footnotetext{
${ }^{1}$ Submetido em: 24/04/2018 - Aceito em: 06/05/2018 - Publicado em: 11/01/2019
}

\begin{tabular}{l|c|c|c|c|c|c} 
(C) Rev. Educ. Perspec. & Viçosa, $M G$ & v.9 & n.2 & p.381-395 & maio/ago. 2018 & eISSN 2178-8359 \\
\hline
\end{tabular}




\section{CONSIDERAÇÕES INICIAIS: A HISTÓRICA DICOTOMIA ENTRE TEORIA E PRÁTICA}

O êxito da educação escolar depende de muitos fatores e variáveis, mas, sem dúvida, possui relação direta com as concepções teóricas e práticas do professor. Entendemos, por isso, que a formação docente é uma questão-chave com reflexos no modelo de escola e de educação escolar.

A abordagem da sempre difícil relação entre teoria e prática tem sido, historicamente, alvo de muitos debates e estudos. A questão parece envolver mais uma dessas aporias que não encontram uma saída e nem se resolvem, de forma adequada e satisfatória, quando consideradas sob o enfoque de uma lógica clássica disjuntiva. Nosso propósito é buscar compreender essa relação partindo dos princípios da teoria da complexidade desenvolvida por Edgar Morin (2006).

A temática sobre o saber-fazer docente remete-nos ao núcleo central da questão do conhecimento em si e nos desafia a refletir, ainda que de forma ampla, sobre perguntas do tipo: Como foi e como está sendo exercido e compreendido o processo de assimilação e construção do conhecimento na educação escolar? Os docentes compreendem os modelos, as condições, os limites e o sentido do próprio pensar? Quais são as convicções dos professores no campo epistemológico em um contexto atual de tantas questões emergentes? Em nosso entendimento, compreender e saber lidar com a questão do conhecimento é um desafio e um pré-requisito para uma ação docente responsável e, sem dúvida, pressuposto básico para o êxito da educação em qualquer época.

Muitos pedagogos e educadores continuam apostando naquilo que se convencionou denominar de fundamentos filosóficos e biopsicossociais da educação, inseridos nos currículos das Licenciaturas com a finalidade de fornecer bases teóricas sólidas para a prática escolar. A inserção de tais fundamentos demonstrava, de certo modo, a prioridade de uma formação geral sólida e se contrapunha aos movimentos que tentavam promover o recuo da formação teórica. Tal posicionamento pressupõe que a teoria deve preceder a prática ou que uma boa teoria é sempre um pressuposto e se traduz necessariamente em prática. Os currículos das Licenciaturas com este viés priorizam os componentes de fundamentação e formação teórica e colocam a prática docente como culminância de aprendizagem, em um ou dois semestres no final do curso.

Num contexto mais atual, porém, os discursos predominantes e emergentes indicam e justificam que a atuação docente deve ser desenvolvida com ênfase numa racionalidade operacional, com predomínio de um saber prático. Saber-fazer parece ser a expressão vigente em muitos espaços e/ou instituições educacionais. Sendo assim, prima-se pelo

\begin{tabular}{l|c|c|c|c|c|c} 
() Rev. Educ. Perspec. & Viçosa, $M G$ & v.9 & n.2 & p.381-395 & maio/ago. 2018 & eISSN 2178-8359 \\
\hline
\end{tabular}


desenvolvimento de habilidades e competências que se traduzam em eficiência e resultados práticos, pois, de acordo com tal concepção, isso seria pré-requisito para quem almeja inserirse em qualquer contexto social e profissional.

Essa tendência tem sido a tônica que perpassa os textos mais recentes ${ }^{\mathrm{i}}$ e que se traduz em orientações nos documentos oficiais. A Resolução CNE/CP 1/2002, ao instituir as Diretrizes Curriculares Nacionais para a Formação de Professores da Educação Básica, sugere no seu artigo 12 que a formação do professor ocorra com base em componentes práticos oferecidos desde o início do curso e não apenas em seu final. Enfatiza a esse respeito:

\footnotetext{
$\S 1^{\circ}$ A prática, na matriz curricular, não poderá ficar reduzida a um espaço isolado, que a restrinja ao estágio, desarticulado do restante do curso.

$\S 2^{\circ}$ A prática deverá estar presente desde o início do curso e permear toda a formação do professor.

$\S 3^{\circ}$ No interior das áreas ou das disciplinas que constituírem os componentes curriculares de formação, e não apenas nas disciplinas pedagógicas, todas terão a sua dimensão prática (BRASIL, 2002, p. 5).
}

Esta recomendação visa dar outra direção para o viés teórico dos cursos que formam professores. "Muita teoria e pouca prática formam os professores", proclamam as manchetes de revistas e jornais. Há um clamor da comunidade educativa, de empresários e de gestores no sentido de fazer com que os currículos escolares deem mais ênfase às atividades técnicas e instrumentais. Trata-se de uma concepção curricular marcadamente instrumental, na qual os chamados conteúdos teóricos de formação geral são desbancados e/ou subsumidos em favor de aprendizagens específicas com finalidade prática e direcionadas para o exercício de uma profissão.

O horizonte de compreensão de cada uma dessas duas posturas analisadas revela, em nosso entendimento, um grande equívoco em relação ao conceito que podemos ter sobre o que é a teoria e o que é a prática e por que elas continuam sendo vistas de forma tão dissociada e antagônica. A transcendência dessas duas concepções aparentemente irreconciliáveis exige a compreensão sobre o que é o conhecimento e como ele se operacionaliza. O caminho de uma ação docente que contemple a indissociabilidade entre teoria e prática requer, portanto, uma reforma no modo de conceber, organizar e processar o pensamento e o conhecimento.

A superação da dicotomia teoria versus prática pressupõe uma revisão dos nossos paradigmas e modelos de pensamento. É necessário que nossa mente investigativa comece a se questionar sobre a forma como pensa, o resultado do que pensa e, como corolário disso, assumir o desafio de pensar outro modo de processar, organizar o pensamento e elaborar os saberes. A preocupação não pode se voltar unicamente para o fazer ou para o puro saber, mas tem de contemplar um saber-fazer, aliando os saberes teóricos com os técnico-instrumentais. Com isso, podemos nos surpreender com as possibilidades, armadilhas, incertezas e ilusões do próprio pensar.

\begin{tabular}{l|c|c|c|c|c|c} 
(C) Rev. Educ. Perspec. & Viçosa, $M G$ & v.9 & n.2 & p.381-395 & maio/ago. 2018 & eISSN 2178-8359 \\
\hline
\end{tabular}


As interrogações que nos fazemos nos remetem à raiz do paradigma da complexidade, para apresentar argumentos de validação e sustentação da vida e de suas manifestações socioculturais. Esse espírito investigativo também faz emergir outras dúvidas e interrogações, tais como: É possível abordar, de e em forma complexa, o problema que pretendemos compreender? Quais os sentidos e caminhos possíveis que esta reflexão pode assumir se for pautada pelo paradigma linear, binário e, portanto, simplificador? Por conta disso, é extremamente importante fazermos uma tentativa de reflexão em relação ao pensar corrente e uma aposta numa outra racionalidade, que inclua o sentido de dimensões aparentemente contrárias e antagônicas, todavia, intercomplementares, como saber o fazer e fazer o saber, teoria e prática, local e universal, uno e diverso, singular e plural, Ciências Humanas e Exatas, entre outras manifestações aparentemente contrárias e separáveis. Para tamanho desafio é necessário um pensar diferente daquele que usualmente utilizamos.

Pensar é, sem dúvida, uma condição humana. Um dos grandes desafios de ser humano é, desde sua origem, trilhar novas formas de racionalidade, sair da vala comum e uniformizadora dos modelos tradicionais de pensar. Ousar pensar de outras formas e, de forma simultânea, tomar consciência sobre por que pensamos o que pensamos. O pensar único, monovalente e simplificador é produto da cegueira de um modo de aprender e de conhecer e, quem sabe, também uma forma de declarar o fim da História. É necessário, pois, rever o modo dominante de pensar. A civilização e a pluralidade das formas e modos de pensar podem ser caminhos de o ser humano viver e atuar neste mundo no qual o diálogo deve prevalecer.

O pensar acaba se colocando como uma condição de possibilidade de cada um compreender a si mesmo e o processo histórico que resultou nos racionalismos todos, bem como seus desdobramentos na cultura e na educação escolar desde a modernidade até a contemporaneidade. Nesse sentido, o pensar se transforma em reflexão, em Filosofia, em paixão pelo saber, em ato emancipatório que outorga o direito a cada sujeito de pensar bem, de pensar por si e de pensar com os outros os "saberes-fazeres".

\section{PONTO DE PARTIDA: ALGUMAS INTERROGAÇÕES ACERCA DO CONHECIMENTO}

Quais modelos de "saberes-fazeres" podem ser orientadores da prática docente? É possível continuar pensando as dimensões da teoria e da prática de forma dissociada uma da outra? Qual a importância de saber fazer sem deixar de saber pensar e pensar o fazer?

Alguns especialistas parecem ter sempre uma resposta pronta quando se trata de apresentar alguma solução para os problemas da educação. Isso é decorrência de uma racionalidade que

\begin{tabular}{l|l|l|l|l|l|l} 
(C) Rev. Educ. Perspec. & Viçosa, $M G$ & v.9 & n.2 & p.381-395 & maio/ago. 2018 & eISSN 2178-8359 \\
\hline
\end{tabular}


predomina em nossa forma de pensar, em nossas práticas docentes, tendo em vista que o currículo dos cursos de formação dos docentes tem a marca da tradição iluminista na educação escolar.

Sabemos hoje que não existe, por ora, uma ciência da ciência, uma ciência que a tutele e a salvaguarde ou, simplesmente, uma ciência produtora de verdade universal e inquestionável, em qualquer campo do saber. Ela é sempre biodegradável, recorrente e parcial. Por consequência, não pode haver tribunal que condene ou salve algum paradigma de conhecimento ou um modelo de ciência. As melhores teorias, inclusive aquelas que proporcionam tecnologias confiáveis e eficientes no campo das ciências das engenharias ou biogenéticas, estão sempre se renovando. Embora produzam resultados úteis, é provável que num futuro não muito longínquo sejam substituídas por outros modelos. Parece ter sido esse o caminho e o destino de quase todas as teorias. E essa é uma verdade que perpassa todas as formas e áreas do conhecimento.

O que é sensato em termos de conhecimento, na concepção de Morin (2003), é cultivar uma racionalidade aberta para poder perceber e captar a pluralidade e a diversidade da realidade e, sobretudo, estar alerta para os modelos mutiladores e simplificadores do pensamento linear, binário, redutivo e disjuntivo. Por esta razão é necessário procurar penetrar nos insondáveis mistérios do conhecimento e repensar o processo de assimilar e construir novos saberes.

É preciso, parafraseando Morin (2003), evitar vícios, dentre eles, a "idealização", a "racionalização" e a "normalização" do conhecimento. Na visão deste pensador, quando pretendemos mensurar ou avaliar o processo do conhecer e do conhecimento, incorremos nas seguintes crenças: de "idealizar", apostando que o real é ou pode ser sempre e plenamente inteligível, ou seja, pressupor que a realidade é totalmente objetiva e a mesma para todos; de "racionalizar", isto é, pretender encerrar toda a complexidade do real num paradigma ou na coerência de um sistema, sem atentar para as desordens e incertezas; e de "normalizar", acreditando na objetividade dos fatos e fenômenos e não estando aberto para o estranhamento, o mistério e as irrupções.

O grande desafio, portanto, é conhecer a forma como conhecemos e, a partir daí, reorganizar nosso modo de pensar; é reaprender a pensar para reaprender a aprender. Ainda de acordo com Morin (2000b), a questão fundamental que carece ser enfrentada é a de uma reforma do pensamento que possibilite compreender a complexidade do mundo, a fim de enfrentar as problemáticas que ele apresenta. Nesse viés, a reforma do pensamento é um pré-requisito essencial para estabelecer princípios organizadores do conhecimento que sejam pertinentes. O fundamental nos dias de hoje, segundo Morin (2003, p. 35, grifo do autor) “[...] não é apenas aprender, não é apenas reaprender, não é apenas desaprender, mas reorganizar nosso sistema mental para reaprender a aprender".

\begin{tabular}{l|c|c|c|c|c|c} 
(C) Rev. Educ. Perspec. & Viçosa, $M G$ & v.9 & n.2 & p.381-395 & maio/ago. 2018 & eISSN 2178-8359 \\
\hline
\end{tabular}


Para evitar distorções simplificadoras sobre a realidade, Morin (2000b) insiste na necessidade de uma reforma do pensamento para reformar a educação e vice-versa. É preciso civilizar o pensamento; formar uma cabeça bem-feita, apta a compreender a complexidade da realidade, para ser capaz de resolver os problemas que se apresentam. Não se trata de uma cabeça enciclopédica, plena de conhecimentos fossilizados, e sim, de uma cabeça habilitada a produzir um conhecimento pertinente; disposta a pensar sob o prisma da complexidade, situando cada informação em seu contexto específico e permanecendo atenta à possibilidade e à necessidade de inter-relações; interessada, ainda, na coexistência de métodos distintos de conhecer, que ao conceberem explicação e compreensão, análise e síntese, experiência e analogia dialogicamente, têm aí um trunfo para o desenvolvimento dos saberes.

Esse aprendizado passa pelo resgate de alguns princípios elementares sobre o modo como aprendemos e, sobretudo, pela adoção de um método para conhecer: "Hoje, a nossa necessidade histórica é de encontrar um método que detecte e não que oculte as ligações, as articulações, as solidariedades, as implicações, as imbricações, as interdependências, as complexidades" (MORIN, 2003, p. 29).

Morin argumenta que, em matéria de conhecimento, nós temos a necessidade urgente de investigar e investir no impensado do pensamento, aquilo que o comanda e o controla. Segundo o autor, o problema é que "Nós nos servimos de nossa estrutura de pensamento para pensar. Será preciso também nos servirmos de nosso pensamento para repensar nossa estrutura do pensamento. Nosso pensamento deve retornar à sua fonte em forma de circuito interrogativo e crítico" (MORIN, 2003, p. 35). No reino do intelecto, ao contrário do que acreditamos, é o inconsciente que irriga e governa o que se crê em plena consciência. $\mathrm{O}$ conhecimento que "possuímos nos possui” e pode nos cegar tanto quanto nossa ignorância.

Utilizando-se do princípio do elo recorrente ${ }^{\mathrm{ii}}$ Morin (2013, p. 171) não tem dúvida em afirmar que "[...] quanto mais profundamente elucidamos nosso espírito, mais profundamente elucidamos nosso mundo e que, reciprocamente, quanto mais elucidamos nosso mundo mais profundamente elucidamos nosso espírito". Não seria essa uma categoria para refletirmos a relação entre saber e fazer, ou então, entre teoria e prática?

\section{A DIFÍCIL TAREFA DE COMPREENDER E DE SUPERAR A DICOTOMIA TEORIA VERSUS PRÁTICA}

Na ótica do pensar complexo, a questão do saber-fazer docente pode ser compreendida como uma realidade de dupla face ou como as duas faces de uma mesma moeda. Há uma indissociabilidade entre a dimensão do saber e do fazer, algo assim como sujeito e objeto, 
ensino e aprendizagem, pesquisa e conhecimento, teoria e prática, causa e efeito, uno e diverso, local e global, pensamento e ação.

Essas dicotomias só não se reconhecem como complementares quando vistas sob o ponto de vista de pensar binário e linear, ou seja, de acordo com o modelo de pensamento que simplifica e opera pelo princípio do terceiro excluído, do tipo ou é isso ou é aquilo. Para a lógica clássica, algo não pode ser e não ser ao mesmo tempo. As dicotomias, porém, podem ser superadas quando temos uma noção sistêmica e complexa do conhecimento e que opera pelo princípio dialógico e conetivo, em que algo é isso e aquilo ao mesmo tempo. Essas dicotomias formam um elo recorrente entre si, são causadas e causantes uma da outra.

A dicotomia excludente que se forma em torno do sentido de saber e fazer como algo descolado e disjunto só pode ser fruto de um pensar simplificador, disjuntivo e reducionista. Segundo Morin (2006), quando pensamos de forma complexa percebemos a tessitura comum que define como sendo inseparavelmente associados o indivíduo e o contexto, o analítico e o sintético, a ordem e a desordem, o natural e o cultural, o sujeito e o objeto, o professor e o aluno e todos os demais tecidos que regem os acontecimentos, as ações e as interações organizacionais que constituem a trama da vida. Assim, não podemos dissociar os diferentes tipos de saberes: científicos, filosóficos, poéticos, míticos, entre outros. Todos os saberes, em sua especificidade, contribuem para uma compreensão complexa do mundo e de seus fenômenos.

Dentre os mais importantes princípios-guia, vetores da complexidade ou operadores cognitivos da complexidade, ${ }^{\text {iii }}$ para efeitos da compreensão da temática que estamos analisando, é importante compreender o significado do princípio da "dialogia". A "dialogia" é um vetor da complexidade que reúne noções que se repelem entre si, são antagônicas, concorrentes, contraditórias e, ao mesmo tempo, são necessariamente complementares para perceber o universo e seus fenômenos, como a dialógica da teoria/prática, ordem/desordem, singular/plural, eu/tu, homem/mulher, professor/aluno, etc. São polos contrários, no entanto, intercomplementares, que convivem numa lógica de inclusão/exclusão (MORIN, 2006, p. 7376).

Por outro lado e de uma forma bem peculiar, a questão da unidade teoria-prática também nos remete aos princípios da dialética materialista de Marx e se expressa no termo práxis. $\mathrm{O}$ sentido da palavra práxis, no movimento dialético, é extraído do conceito de modo de produção. As transformações das formas de produção da existência humana, segundo Saviani (1991), provocam e geram novas formas de educação. Estas, por sua vez, vão exercer influência sobre o modo de produção vigente ${ }^{\text {iv }}$. Pressupõe, portanto, que um movimento produz outro que o produz. São momentos imbricados entre si, condicionados e condicionantes, instituídos e instituintes; não há como descolar um do outro, pois formam

\begin{tabular}{l|l|l|l|l|l|l} 
(C) Rev. Educ. Perspec. & Viçosa, $M G$ & v.9 & n.2 & p.381-395 & maio/ago. 2018 & eISSN 2178-8359 \\
\hline
\end{tabular}


entre si o chamado elo recorrente. Nesse sentido, conforme Saviani (1991), o que ocorre nesse quesito é que muitos confundem o sentido de teoria com verbalismo e de prática com ativismo. A noção de práxis expressa de forma aproximada a ideia de que teoria e prática são dimensões aparentemente antagônicas, todavia, inseparáveis e complementares.

A afirmação de que a formação do professor, no Brasil, tem muita ênfase teórica e pouca preparação prática suscita a seguinte pergunta: Qual concepção de teoria e de prática está presente nessa afirmação? O que dá origem à compreensão tão desencontrada desses dois termos e que os coloca lado a lado ou frente a frente como duas paralelas que não se tocam?

Severino (2011, p. 39) argumenta que o conhecimento tem a ver com uma intencionalidade da prática simbolizadora, com um sentido projetivo do agir prático e que "[...] a prática humana em geral, se de um lado ela é prática, ela não é qualquer prática. Não é prática mecânica, transitiva; é prática orientada, norteada, pensada, vinculada e dependente de fins intencionais. Ela é práxis”.

Essa mesma linha de raciocínio também pode ser detectada em Luckesi (2011, p. 46-47) quando afirma:

\footnotetext{
Nas relações entre Filosofia e educação só existem realmente duas opções: ou se pensa e se reflete sobre o que se faz e assim se realiza uma ação educativa consciente; ou não se reflete criticamente e se executa uma ação pedagógica a partir de uma concepção mais ou menos obscura e opaca existente na cultura vivida do dia a dia - e assim se realiza uma ação educativa com baixo nível de consciência.
}

Mariotti (2010) criou uma metáfora reveladora e original de como pode ser compreendida a unidade teoria-prática. Segundo o autor, o conhecimento pode ser comparado a uma escada. Numa escada, para que ela se mantenha íntegra, todos os degraus precisam estar interligados. Não é possível separá-los sob pena de desintegrar a escada. Da mesma forma, teoria, procedimentos, resultados, processos e instrumentos estão todos interligados e se autoproduzem, produzindo um ao outro. O campo da reflexão e das ideias está interligado com os métodos e técnicas do que e do como fazer. Estas ferramentas operacionais, por sua vez, estão imbricadas com os produtos, de tal sorte que, para Mariotti (2010), não há nada de puramente "muito teórico" ou algo de "somente prático".

\section{UM CAMINHO POSSÍVEL: O SABER-FAZER DOCENTE PRESSUPÕE UMA EPISTEMOLOGIA COMPLEXA}

É possível pensar num paradigma pedagógico que permita assegurar unidade ao nosso saber e fazer na diversidade e pluralidade cultural do mundo contemporâneo? Qual racionalidade filosófica e pedagógica deve orientar a formação do professor?

\begin{tabular}{l|c|c|c|c|c|c} 
(C) Rev. Educ. Perspec. & Viçosa, $M G$ & v.9 & n.2 & p.381-395 & maio/ago. 2018 & eISSN 2178-8359 \\
\hline
\end{tabular}


Ao refletir sobre os desafios da educação do século 21, Morin (2001) tece críticas à educação escolar, sobretudo ao Ensino Médio, orientado pelos princípios da fragmentação e da compartimentalização dos saberes. A fim de minimizar tais tendências, o autor tem se empenhado arduamente em promover uma reforma universitária visando a explicitar o que entende que seja uma educação voltada e orientada para a formação do pensamento complexo.

Se entendermos por complexidade algo que está tecido junto, entretecido e, portanto, constituído de um todo polissêmico, de conjuntos de partes que se inter-relacionam entre si, tanto na cosmogênese do universo quanto no tecido social, então é necessário lançar mão de princípios cognitivos que possam permitir a sua compreensão. A complexidade, assim, "é uma característica sistêmica e um fator constitutivo da vida, constitutivo dos diferentes fenômenos, eventos e processos" (MORAES, 2010, p. 16). Daí a importância do pensamento complexo como uma possibilidade que transcende tanto o pensamento linear quanto o pensamento sistêmico.

A partir desta configuração torna-se necessário investigar e aprofundar os modelos mentais que mais frequentemente são utilizados na educação escolar contemporânea; convém, complementarmente, aprofundar estudos sobre a possibilidade de instituir outra racionalidade com caráter plural, sistêmico e complexo, que possa ressignificar algumas temáticas nucleares do processo de educação escolar, dentre elas a questão do saber-fazer.

A perspectiva paradigmática da complexidade reúne elementos de diferentes teorias filosóficas e científicas elaboradas ao longo da história do pensamento humano. Ela tem o propósito de repensar os pressupostos orientadores do campo científico atual, estabelecendo princípios para uma ciência nova e global. Esta, segundo Morin (2006), deverá surgir da metamorfose ou da revolução conceitual dos pressupostos fundados nos princípios da ciência clássica.

Morin, na obra "Ciência com consciência" (2000a), esclarece que a complexidade não é uma palavra-chave que vai explicar tudo, mas, é ela que vai nos desafiar a explorar e buscar a compreensão dos mistérios do mundo. Alerta, ainda, para que sejam superados dois grandes equívocos sobre a complexidade. O primeiro mal-entendido é o de concebê-la [...] "como receita, como resposta, em vez de considerá-la como desafio e como uma motivação para pensar" (MORIN, 2000a, p. 176). O segundo "[...] consiste em confundir a complexidade com a completude" (MORIN, 2000a, p. 176). E acrescenta: “[...] o problema da complexidade é, antes de tudo, o esforço para conceber um incontornável desafio que o real lança a nossa mente” (MORIN, 2000a, p. 176). Desta forma, conclui: “[...] é evidente que a ambição da complexidade é prestar contas das articulações despedaçadas pelos cortes entre disciplinas, entre categorias cognitivas e entre tipos de conhecimento. De fato, a aspiração à

\begin{tabular}{l|l|l|l|l|l|l} 
(C) Rev. Educ. Perspec. & Viçosa, $M G$ & v.9 & n.2 & p.381-395 & maio/ago. 2018 & eISSN 2178-8359 \\
\hline
\end{tabular}


complexidade tende para o conhecimento multidimensional" (MORIN, 2000a, p. 176-177). Mais que a ambição de explicar tudo, a complexidade caracteriza-se por uma atitude que tem a preocupação de compreender algo que não foi ou não está sendo bem elucidado sobre os fenômenos da realidade, tendo em vista que, ao contrário do que outros tipos de conhecimento asseguram, para a complexidade nada é simples: tudo é algo complexo.

Morin (2002) denomina de conhecimento complexo aquele que: reconhece que o sujeito está incluído no objeto; que contempla a unidade e a diversidade humanas; que concebe e percebe as dimensões humanas de forma não fragmentada; que compreende as dialógicas humanas de sapiens-demens, faber-ludens, economicus-consumans, prosaicus-poeticus e outras; que considera as diferentes dimensões do conhecimento, como a mítica, a religiosa, a científica e a filosófica, ressignificando termos e conceitos distorcidos pela ciência ou pelo senso comum.

O pensamento complexo, portanto, não pode prescindir de um olhar epistemológico com característica inter/transdisciplinar. A complexidade não é apenas propriedade de alguns fenômenos, e sim, está presente em toda a realidade biológica e social. Por essa razão, Morin (1999) propõe uma revisão do paradigma da simplificação, do princípio das abordagens disciplinares dos diferentes saberes e das especializações do conhecimento que retalham, cortam, reduzem, disjuntam e fragmentam o objeto complexo. O retalhamento do conhecimento impede a apreensão do complexo e, por consequência, a produção do conhecimento pertinente. $\mathrm{O}$ objeto de conhecimento não pode cair prisioneiro de uma disciplina especializada ou de uma área enclausurada do saber, uma vez que "tudo está tecido junto" e, portanto, tudo é complexo. Morin (1999, p. 208) defende que é necessário pôr em questão o princípio das disciplinas que recortam o objeto complexo, “[...] o qual é essencialmente constituído pelas inter-relações, pelas interacções, pelas interferências, pelas complementaridades, pelas oposições, entre elementos constitutivos, cada um dos quais é prisioneiro de uma disciplina particular".

Perceber algo num contexto é perceber esse algo numa relação, num sistema ou num sistema de sistemas. Por isso, o foco da observação deverá centrar-se na percepção das interconexões ecossistêmicas, das interligações, das redes de redes. A pertinência do conhecimento consiste em religar as partes ao todo e o todo às partes, situando as informações e dados num contexto global - histórico e geográfico - de forma simultaneamente analítica e sintética.

No entendimento de Vasconcellos (2002, p. 111, grifo do autor):

Para pensar complexamente, precisamos mudar crenças muito básicas: em vez de acreditar que vamos ter como objeto de estudo o elemento, ou o indivíduo, e que teremos de delimitá-lo muito bem, precisamos passar a acreditar que estudaremos ou trabalharemos sempre com o objeto em contexto. 
Uma epistemologia complexa busca superar as concepções mutilantes que impedem a compreensão, pois disjuntam e separam o todo de suas partes constitutivas. Por outro lado, procura ir além das concepções holísticas que contemplam o todo em detrimento da compreensão das partes. Nesta proposta também entra o reconhecimento do princípio da incerteza presente em nossa realidade, que instiga a considerar paralelamente o saber e o não saber, o saber e o fazer, o conhecido e o desconhecido, o certo e o incerto, não como binômios excludentes, mas, retroativos e complementares.

A teoria da complexidade, ao promover o desenvolvimento do pensamento complexo, pode despertar-nos para que tomemos consciência dos recortes simplificadores que o conhecimento opera ao dialogar com o real. Esse é um dos desafios que a epistemologia complexa se propõe a superar: integrar, religar, fazer comunicar as instâncias e esferas separadas do conhecimento como a questão da teoria e da prática. É desta forma que entendemos que a teoria da complexidade pode promover um novo olhar investigativo para a construção do conhecimento no processo de ensino-aprendizagem, na pesquisa e na própria ciência, com reflexos na compreensão e operacionalização do processo educacional e do saber-fazer docente na contemporaneidade.

\section{CONSIDERAÇÕES FINAIS PROVISÓRIAS}

Em nossa percepção, para alguns professores o trabalho docente parece consistir numa tarefa predominantemente operacional, centrado numa epistemologia da prática que visa buscar resultados decorrentes de decisões pedagógicas apoiadas em objetivos, teorias, experiências, estágios práticos e circunstâncias imediatas. Na percepção de outros professores o trabalho docente tende a fundamentar-se no conhecimento de teorias e concepções pedagógicas.

Se, conforme Morin (2004), os objetivos e propósitos da educação escolar devem ter seu foco na natureza e na dignidade humanas, então é necessário repensar qual a racionalidade que pode orientar a formação docente. Muitos professores que atuam na educação escolar foram formados num modelo de conhecimento disciplinar e simplificador e, de forma consciente ou não, estão dando continuidade ao mesmo modelo de uma racionalidade científico/técnico/instrumental que separa e dicotomiza a teoria da prática e vice-versa. Não temos dúvida quanto à contribuição da razão instrumental e normativista na concepção e construção dos nossos referenciais pedagógicos e dos métodos e técnicas aos quais recorremos diariamente. Esse quadro é característico dos aportes e dos espaços da tecnologia educacional dos anos 70 do século passado e das novas tecnologias da educação e da comunicação, particularmente com a informática. 
Os saberes e fazeres da nossa ação pedagógica são diversos e profundamente complexos. Por essa razão, o operar com base no pensamento complexo, ancorado nos princípios cognitivos da complexidade, pode nos auxiliar na compreensão e na ressignificação tanto da engenharia complexa da organização e do funcionamento da escola quanto das questões nucleares do processo de educação escolar. As implicações da complexidade resultam em mudanças paradigmáticas e programáticas da educação, ou seja, elas estão diretamente conectadas com o saber e o fazer docente.

A complexidade é um fenômeno constitutivo da vida e, portanto, é também constitutivo do pensamento, do conhecimento e da ação. Ao fazer referência às contribuições do pensamento complexo para o processo de educação escolar, Moraes (2010, p. 19) observa: "Tal compreensão certamente afeta os nossos esquemas lógicos de reflexão e obriga-nos a uma redefinição epistemológica e metodológica em educação, sem precedentes". Sob a ótica da complexidade, a dicotomia saber-fazer se desfaz, ou melhor, é superada na medida em que se forma um anel recursivo entre a teoria e a prática. As relações entre o fazer e o pensar ocorrem de forma indissociável.

Entre os desafios do saber-fazer docente na contemporaneidade está o propósito de relacionar o saber teórico e proposicional que caracteriza cada teoria com o saber fazer que se manifesta na prática profissional docente. $\mathrm{O}$ exercício da prática precisa estar articulado com a teorização no que se refere à formação do professor, a fim de que ela não fique submissa ao pragmatismo nem cultive uma aversão à dimensão teórica. Sendo assim, convém ultrapassar a dicotomia instaurada entre saber e fazer, que insiste em jogá-los para polos opostos e excludentes. A qualidade da formação do professor passa pelo estudo, pela reflexão e aprofundamento teórico, e, complementarmente, requer uma competência prática. Se entendidas de modo isolado, essas dimensões revelam-se insuficientes para as necessidades pedagógicas vigentes.

Não basta apenas aplicar resultados teóricos em discursos e práticas docentes, muito menos quando estas provêm de outros contextos educacionais; assim como não é suficiente formular teorizações generalizadas com base em situações concretas e particulares. A atuação docente ganha mais sentido quando o professor desenvolve modos diferentes de pensar e de interrogar seu exercício profissional, teorizando sua prática cotidiana e, recursivamente, incorporando outras concepções e critérios em seu fazer.

O amplo espectro de saberes que circundam e constituem a formação do professor fazem dele um arauto da multi/inter/transdisciplinaridade, expressão da complexidade do mundo contemporâneo. Os princípios cognitivos da teoria da complexidade podem promover uma significativa mudança e virada paradigmática nas formas de acessar, sistematizar, construir e 
ministrar o conhecimento, podendo ser balizadores dos processos de educação escolar e da formação de professores.

Um pensamento deste nosso novo tempo exige vigilância e reflexividade de modo a contemplar as questões emergentes. Para isso não há receitas prontas, nem aplicação prática e, menos ainda, um programa instituído. Há planos e estratégias para pensar e compreender a complexidade do mundo com um conhecimento pertinente. Mais do que uma solução, o pensamento complexo apresenta-se como uma interrogação, um desafio e um caminho aberto, a fim de buscar e oportunizar alternativas de ação mais compatíveis com o nosso tempo nas nossas instituições escolares.

\section{REFERÊNCIAS}

BRASIL, Ministério da Educação. Conselho Nacional de Educação. Parecer CNE/CP de 18 de fevereiro de 2002. Diretrizes Curriculares Nacionais para a Formação de Professores da Educação Básica, em nível superior, curso de licenciatura, de graduação plena. Brasília, 2002. Disponível em: http://portal.mec.gov.br/cne/arquivos/pdf/009.pdf. Acesso em: 4 jul. 2014.

COLL, Cesar. O construtivismo na sala de aula. São Paulo: Ática, 2006.

LUCKESI, Cipriano Carlos. Filosofia da educação. 2. ed. São Paulo: Cortez, 2011.

MARIOTTI, Humberto. Pensando diferente: para lidar com a complexidade, a incerteza e a ilusão. São Paulo: Atlas, 2010.

MORAES, Maria Cândida. Edgar Morin: peregrino e educador planetário. São Paulo: Editora Meca, 2010.

MORIN, Edgar. Meus filósofos. Tradução: Edgard de Assis Carvalho e Mariza Perassi Bosco. Porto Alegre: Sulina, 2013.

MORIN, Edgar. O método I. A natureza da natureza. Tradução: Ilana Heineberg. 2. ed. Porto Alegre: Sulina, 2003.

MORIN, Edgar. Os sete saberes necessários à educação do futuro. São Paulo/Brasília: Cortez/Unesco, 2004.

MORIN, Edgar. Introdução ao pensamento complexo. Tradução: Eliane Lisboa. Porto Alegre: Sulina, 2006.

MORIN, Edgar. Ciência com consciência. Tradução: Maria D. Alexandre e Maria Alice S. Dória. Rio de Janeiro: Bertrand Brasil, 2000a.

\begin{tabular}{l|c|c|c|c|c|c} 
(C) Rev. Educ. Perspec. & Viçosa, $M G$ & v.9 & n.2 & p.381-395 & maio/ago. 2018 & eISSN 2178-8359 \\
\hline
\end{tabular}


MORIN, Edgar. A cabeça bem-feita: repensar a reforma, reformar o pensamento. Tradução: Eloá Jacobina. 2. ed. Rio de Janeiro: Bertrand Brasil, 2000b.

MORIN, Edgar. A religação dos saberes. O desafio do século XXI. Tradução: Flávia Nascimento. Rio de Janeiro: Bertrand Brasil, 2001.

MORIN, Edgar. O método V. A humanidade da humanidade. Tradução: Juremir Machado da Silva. Porto Alegre: Sulina, 2002.

MORIN, Edgar. O paradigma perdido: a natureza humana. Tradução: Hermano Neves. Lisboa: Publicações Europa-América, 1999.

MORIN, Edgar; LE MOIGNE, Jean-Louis. A inteligência da complexidade. São Paulo: Petrópolis, 2000.

PERRENOUD, Philippe. Construir as competências desde a escola. Tradução: Bruno Charles Magne. Porto Alegre: Artes Médicas, 1999.

SAVIANI, Dermeval. Pedagogia histórico-crítica: primeiras aproximações. São Paulo: Cortez: Autores Associados, 1991.

SEVERINO, Antônio Joaquim. Filosofia da Educação: o desafio do pensar a educação nos países e comunidades lusófonas. In: SEVERINO, Antônio Joaquim; ALMEIDA, Cleide Rita Silvério de; LORIERI, Marcos Antônio (Org.). Perspectivas da Filosofia da Educação. São Paulo: Cortez, 2011. p. 23-45.

VASCONCELLOS, Maria José Esteves de. Pensamento sistêmico: o novo paradigma da ciência. 4. ed. Campinas: Papirus, 2002.

\section{NOTAS}

${ }^{\mathrm{i}}$ Dentre os principais autores que inspiram a atual normatização da formação do professor destacamos: Philippe Perrenoud com o livro "Construir as competências desde a escola" (Porto Alegre: Artes Médicas, 1999) e Cesar Coll com a obra organizada "O construtivismo na sala de aula" (São Paulo: Ática, 2006).

ii "O elo recursivo ou recorrente" é uma noção explicativa dos processos de auto-organização e de autoprodução. Nesses processos os efeitos retroagem sobre as causas determinando que os produtos sejam concomitantemente produtores daquilo que os produz. O produto é produtor do próprio processo que o produz. Esse fato gera a chamada causalidade circular recursiva, que nos ajuda a compreender um fenômeno como um "redemoinho", em que cada momento é, ao mesmo tempo, efeito e causa do momento seguinte. Dessa forma, os estágios ou estados finais alcançados são geradores de novos patamares, o que aponta para a recursividade dos processos.

iii Na obra "A inteligência da complexidade" (MORIN; LE MOIGNE, 2000, p. 48-62) os autores enumeram e analisam treze princípios-guia da complexidade em contraponto com os princípios da simplificação.

${ }^{\text {iv }}$ O Estado do Rio Grande do Sul está propondo uma reforma curricular do Ensino Médio com base na politecnia. Os princípios da educação politécnica, apresentados por Marx e enriquecidos por Gramsci, visam desenvolver o homem integral no intuito de resgatar a dignidade perdida com o processo alienante da produção capitalista. Ela não só é caminho; também é meta. Não é apenas um meio; é também conteúdo. Pela formação

\begin{tabular}{l|c|c|c|c|c|c} 
(C) Rev. Educ. Perspec. & Viçosa, $M G$ & v.9 & n.2 & p.381-395 & maio/ago. 2018 & eISSN 2178-8359 \\
\hline
\end{tabular}


politécnica o aluno tem acesso ao controle manual e intelectual, prático e teórico do processo produtivo, constituindo a partir desse acesso e controle um sujeito com todas as possibilidades de se desenvolver de forma omnilateral.

\section{SOBRE OS AUTORES}

${ }^{1}$ Celso José Martinazzo - Doutor em Educação pela Universidade Federal do Rio Grande do Sul. Professor titular na Universidade Regional do Noroeste do Estado do Rio Grande do Sul. E-mail: martinazzo@unijui.edu.br - ORCID: http://orcid.org/0000-0001-6376-3409

20́berson Isac Dresch - Doutor em Educação nas Ciências pela Unijuí. Professor da Rede Estadual de Ensino do Rio Grande do Sul. E-mail: obersac@yahoo.com.br - ORCID: http://orcid.org/0000$\underline{0002-8312-7132}$ 